\title{
Analisis Perbandingan Kompresi Data dengan Fixed-Length Code, Variable-Length Code dan Algoritma Huffman
}

\author{
J. Jamaluddin \\ Dosen Tetap D3 Manajemen Informatika FE-UMI Medan \\ jac.satuno@gmail.com
}

\begin{abstract}
ABSTRAK
Dalam ilmu komputer, kompresi data adalah sebuah cara untuk memadatkan data sehingga hanya memerlukan ruang yang lebih kecil sehingga lebih efisien dalam menyimpannya atau mempersingkat waktu pertukaran data tersebut.

Dalam tulisan ini, penulis ingin membandingkan efektivitas antara tiga jenis algoritma untuk melakukan kompresi data dalam bentuk teks. Ketiga algoritma tersebut adalah Fixed Length Binary Encoding, Variable Length Binary Encoding dan Algoritma Huffman.
\end{abstract}

Keyword - Kompresi, Algoritma Huffman, Fixed-Length, Variable-Length.

\section{Pendahuluan}

Saat sekarang ini, kebutuhan akan informasi merupakan hal yang diperlukan oleh masyarakat umum. Penggunakan komputer sebagai media informasi digital merupakan salah satu bentuk pendistribusian informasi di masyarakat. Informasi yang beredar dapat berupa teks, suara, dan citra yang dikemas secara digital. Dengan semakin banyaknya informasi yang perlu disimpan secara digital, secara otomatis hal ini akan memerlukan media penyimpanan yang lebih besar lagi. Oleh karena itu diperlukan alternatif penyimpanan data yang dapat meningkatkan efisiensi dari penggunaan media penyimpanan.

Salah satu cara yang digunakan untuk mengefisiensikan media penyimpanan adalah teknik kompresi data. Dengan melakukan kompresi data, maka kita dapat memperkecil ukuran data, dengan demikian kita dapat memaksimalkan penyimpanan data pada suatu media penyimpanan. Selain berguna pada proses penyimpanan data, kompresi data juga dapat mempercepat proses pentransmisian data pada komunikasi data di sistem jaringan dikarenakan data yang ingin ditransmisikan memiliki ukuran yang lebih kecil. Walaupun banyak kelebihan yang ditawarkan oleh teknik kompresi data ini, tetapi pada proses kompresi data diperlukan waktu untuk proses kompresi data maupun untuk mengembalikan data ke bentuk awal.

Pada penelitian kali ini, penulis mencoba untuk membandingkan efektivitas beberapa metode kompresi data diantaranya Fixed Length Binary Encoding, Variable Length Binary Encoding dan teknik kompresi data dengan Algoritma Huffman untuk jenis data berupa teks.

\section{Kompresi Data}

Dalam ilmu komputer, kompresi data adalah cara untuk memadatkan data sehingga hanya memerlukan ruang penyimpanan lebih 
kecil sehingga lebih efisien dalam penyimpanan maupun dalam proses transfer data pada jaringan. ${ }^{[]}$. Prinsip dasar kompresi data adalah memperkecil besar bit data untuk merepresentasi tiap-tiap karakter pada teks yang ingin dikompresi. Dalam hal ini, terdapat banyak cara yang dilakukan untuk melakukan kompresi data tesebut.

Dalam sistem klasik proses kompresi data dilakukan secara Fixed Length Code. Dengan teknik Fixed Length code, setiap karakter di representasikan dengan sebuah bit biner yang unik. Misalnya teks yang ingin kita kompresi hanya memiliki 6 karakter saja, sehingga apabila kita menggunakan Fixed Length code, setiap karakter akan direpresentasikan dengan 3 bit data, seperti a $=000, \mathrm{~b}=001, \ldots \mathrm{f}=101$.

Sedangkan teknik selanjutnya adalah Variable Length code, teknik ini dianggap lebih efisien dibandingkan dengan Fixed Length code karena pada teknik ini karakter yang memiliki kemunculan yang paling sering akan memiliki besar bit yang paling kecil, seperti $\mathrm{a}=0, \mathrm{e}=10, \mathrm{c}=110, \mathrm{~d}=1110$, $\mathrm{b}=11110$, dan $\mathrm{f}=11111$. Dengan demikian maka teknik ini akan menghasilkan hasil kompresi yang lebih maksimal.

\section{Algoritma Huffman}

Algoritma Huffman, yang dibuat oleh seorang mahasiswa MIT bernama David Huffman pada tahun 1952, merupakan salah satu metode paling lama dan paling terkenal dalam kompresi teks ${ }^{[2]}$. Algoritma Huffman menggunakan prinsip pengkodean yang mirip dengan kode Morse, yaitu tiap karakter ( ymbol) dikodekan hanya dengan rangkaian beberapa bit, dimana karakter yang sering muncul dikodekan dengan rangkaian bit yang pendek dan karakter yang jarang muncul dikodekan.dengan rangkaian bit yang lebih panjang.

Berdasarkan tipe peta kode yang digunakan untuk mengubah pesan awal (isi data yang diinputkan) menjadi sekumpulan codeword, algoritma Huffman termasuk kedalam kelas algoritma yang menggunakan metode ymbol. Metode ymbol adalah metode yang selalu menggunakan peta kode yang sama, metode ini membutuhkan dua fase (two-pass): fase pertama untuk menghitung probabilitas kemunculan tiap ymbol dan menentukan peta kodenya, dan fase kedua untuk mengubah pesan menjadi kumpulan kode yang akan di taransmisikan.

Untuk menentukan nilai bit dari tiaptiap karakter, kita terlebih dahulu membuat pohon biner berdasarkan sering tidaknya sebuah karakter pada teks yang ingin di kompresi. Pohon biner ini biasa disebut pohon Huffman.

Langkah-langkah pembentukan pohon Huffman adalah sebagai berikut:

1. Baca semua karakter di dalam data untuk menghitung frekuensi kemunculan setiap karakter. Setiap karakter penyusun data dinyatakan sebagai pohon bersimpul tunggal. Setiap simpul di-assign dengan frekuensi kemunculan karakter tersebut.

2. Terapkan strategi greedy sebagai berikut : gabungkan dua buah pohon yang mempunyai frekuensi terkecil pada sebuah akar. Akar mempunyai frekuensi yang merupakan jumlah dari frekuensi dua buah pohon penyusunnya. 
3. Ulangi langkah 2 sampai hanya tersisa satu buah pohon Huffman. Agar pemilihan dua pohon yang akan digabungkan berlangsung cepat, maka semua pohon yang ada selalu terurut menaik berdasarkan frekuensi.

Algoritma Huffman:

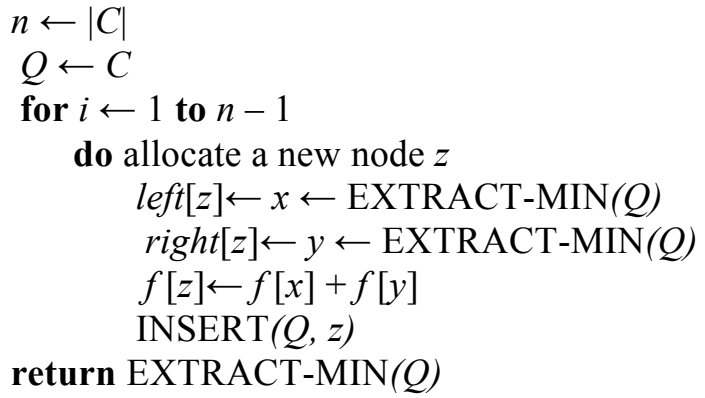

do allocate a new node $z$

left $[z] \leftarrow x \leftarrow$ EXTRACT-MIN $(Q)$ $\operatorname{right}[z] \leftarrow y \leftarrow \operatorname{EXTRACT}-\mathrm{MIN}(Q)$

\section{Proses Coding dan Analisis}

Dalam makalah ini penulis akan mencoba untuk membandingkan ketiga teknik kompresi data tersebut dengan 2 jenis teks yang berbeda, yakni teks dengan persentase kemunculan yang tak seimbang dan teks dengan persentase kemunculan yang seimbang. Kedua teks tersebut adalah:

1. MAGISTER TEKNIK INFORMATIKA USU

\section{KUKU KAKI KAKAK KAKEKKU KAKU}

Tabel frekuensi teks I:

\begin{tabular}{|c|c|c|c|c|c|c|c|c|}
\hline Char & $\mathrm{M}$ & A & $\mathrm{G}$ & I & $\mathrm{S}$ & $\mathrm{T}$ & $E$ & \\
\hline Freq & 2 & 3 & 1 & 4 & 2 & 3 & 2 & \\
\hline Char & $\mathrm{R}$ & $\mathrm{Sp}$ & K & $\mathrm{N}$ & $\mathrm{F}$ & $\mathrm{O}$ & $\mathrm{U}$ & Total \\
\hline Freq & 2 & 3 & 3 & 2 & 1 & 1 & 2 & 31 \\
\hline
\end{tabular}

Tabel 1. Frekuensi Kemunculan Teks I

Dengan Fixed-Length code kita akan mendapatkan kode biner untuk teks I sebagai berikut:

\begin{tabular}{|l|l|}
\hline Char & Kode Biner \\
\hline $\mathrm{M}$ & 0000 \\
\hline
\end{tabular}

\begin{tabular}{|l|l|}
\hline$A$ & 0001 \\
\hline G & 0010 \\
\hline I & 0011 \\
\hline S & 0100 \\
\hline T & 0101 \\
\hline E & 0110 \\
\hline R & 0111 \\
\hline Sp & 1000 \\
\hline K & 1001 \\
\hline N & 1010 \\
\hline F & 1011 \\
\hline O & 1100 \\
\hline U & 1101 \\
\hline
\end{tabular}

Tabel 2. Kode Biner Fixed-Length code teks I

Dari tabel diatas, kita dapat merepresentasikan teks kedua kedalam bentuk biner menjadi $0000000100100011 \ldots$, yang apabila diteruskan kita akan mendapatkan 124 bit biner.

Sehingga dengan teknik FixedLength code, kita akan mendapatkan rasio kompresi terhadap data awal sebesar:

Rasio Kompresi $=\frac{248-124}{248} \times 100 \%=50 \%$

Dengan menggunakan VariableLength code, kita harus terlebih dahulu melakukan Stable Sorting terhadap tabel frekuensi data pertama sehingga didapatkan tabel baru yang telah disorting sebagai berikut:

\begin{tabular}{|c|c|c|c|c|c|c|c|c|}
\hline Char & $\mathrm{I}$ & $\mathrm{A}$ & $\mathrm{T}$ & $\mathrm{Sp}$ & $\mathrm{K}$ & $\mathrm{M}$ & $\mathrm{S}$ & \multirow{1}{*}{} \\
\cline { 1 - 8 } Freq & 4 & 3 & 3 & 3 & 3 & 2 & 2 & \multirow{2}{*}{} \\
\hline Char & $\mathrm{E}$ & $\mathrm{R}$ & $\mathrm{N}$ & $\mathrm{U}$ & $\mathrm{G}$ & $\mathrm{F}$ & $\mathrm{O}$ & Total \\
\hline Freq & 2 & 2 & 2 & 2 & 1 & 1 & 1 & 31 \\
\hline
\end{tabular}

Tabel 3. Frekuensi Kemunculan yang Telah

Disortir pada Teks I

Selanjutnya kita membangun pohon biner untuk tabel tersebut: 
Dari pohon biner VLC tersebut kita dapat menghasilkan tabel kode biner untuk setiap karakter sebagai berikut:

\begin{tabular}{|l|l|}
\hline Char & Kode Biner \\
\hline I & 0 \\
\hline A & 10 \\
\hline T & 110 \\
\hline Sp & 1110 \\
\hline K & 11110 \\
\hline M & 111110 \\
\hline S & 1111110 \\
\hline E & 1111110 \\
\hline R & 11111110 \\
\hline N & 111111110 \\
\hline U & 11111111110 \\
\hline G & 11111111110 \\
\hline F & 111111111110 \\
\hline O & 111111111111 \\
\hline
\end{tabular}

Tabel 4. Kode Biner Variable-Length code untuk teks I

Sehingga dari tabel diatas kita dapat merepresentasikan teks I kedalam bentuk bit biner menjadi $1111101011111111110 \ldots$, dan apabila diteruskan akan menghasilkan bit biner sebesar:

\begin{tabular}{|c|c|c|c|}
\hline Char & Bit & Frekuensi & $\begin{array}{c}\text { Jumlah } \\
\text { bit }\end{array}$ \\
\hline I & 1 & 4 & 4 \\
\hline A & 2 & 3 & 6 \\
\hline
\end{tabular}

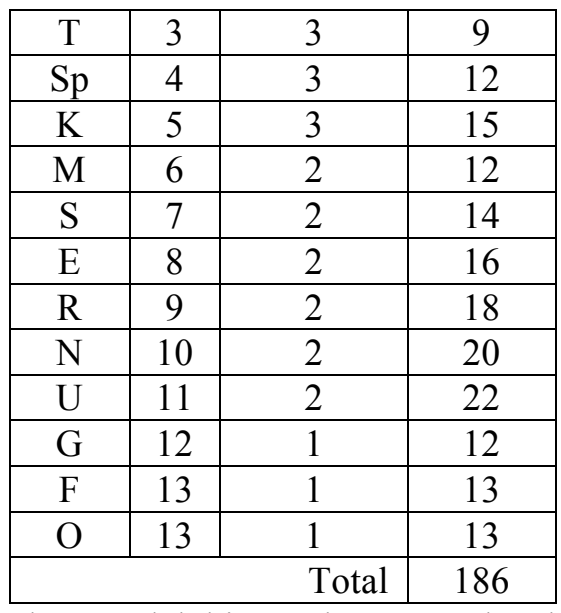

Tabel 5. Jumlah bit untuk VLC pada teks II

Sehingga dengan teknik VariableLength code, kita akan mendapatkan rasio kompresi terhadap data awal sebesar:

Rasio Kompresi $=\frac{248-186}{248} \times 100 \%=25 \%$

Dengan Tabel 3, kita juga dapat melakukan kompresi data dengan algoritma Huffman, sama halnya dengan Variable Length code, dengan algoritma Huffman kita juga menggunakan tabel frekuensi data yang sudah disorting. Dengan langkah-langkah pada algoritma Huffman, kita akan mendapatkan pohon biner (biasa disebut pohon Huffman) sebagai berikut: 


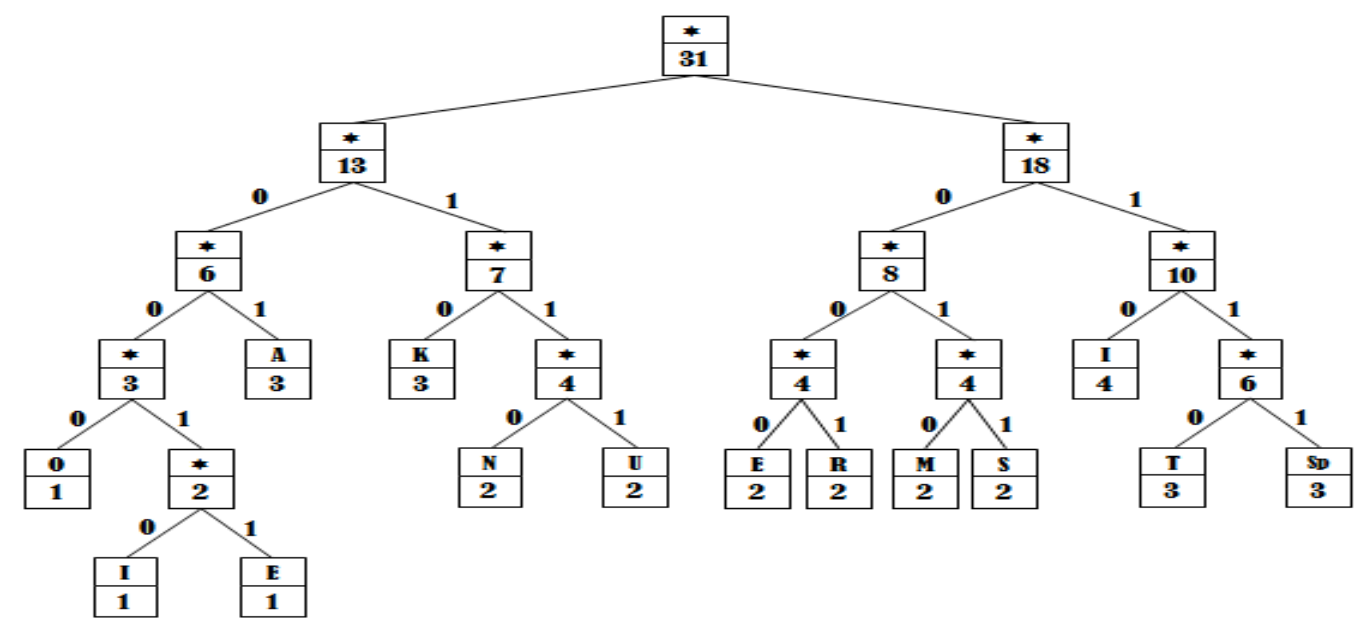

Gambar 2. Pohon Huffman untuk teks I

Dari pohon Huffman diatas, kita bisa merepresentasikan tiap-tiap karakter pada teks dengan kode-kode biner berikut:

\begin{tabular}{|c|c|c|c|c|}
\hline Char & Kode & Bit & Freq & Bit*Freq \\
\hline I & 110 & 3 & 4 & 12 \\
\hline $\mathrm{A}$ & 001 & 3 & 3 & 9 \\
\hline $\mathrm{T}$ & 1110 & 4 & 3 & 12 \\
\hline $\mathrm{Sp}$ & 1111 & 4 & 3 & 12 \\
\hline $\mathrm{K}$ & 010 & 3 & 3 & 9 \\
\hline $\mathrm{M}$ & 1010 & 4 & 2 & 8 \\
\hline $\mathrm{S}$ & 1011 & 4 & 2 & 8 \\
\hline$E$ & 1000 & 4 & 2 & 8 \\
\hline $\mathrm{R}$ & 1001 & 4 & 2 & 8 \\
\hline $\mathrm{N}$ & 0110 & 4 & 2 & 8 \\
\hline $\mathrm{U}$ & 0111 & 4 & 2 & 8 \\
\hline $\mathrm{G}$ & 00010 & 5 & 1 & 5 \\
\hline $\mathrm{F}$ & 00011 & 5 & 1 & 5 \\
\hline $\mathrm{O}$ & 00000 & 5 & 1 & 5 \\
\hline \multicolumn{4}{|r|}{ Total } & 116 bit \\
\hline
\end{tabular}

Tabel 6. Kode Biner algoritma Huffman

Dengan kode biner yang didapatkan dari pohon Huffman, kita bisa merepresentasikan teks pertama dalam bentuk
1010001000101101011..., dan apabila diterukan kita akan mendapatkan panjang data sebesar 116 bits.

Rasio Kompresi $=\frac{248-116}{248} \times 100 \%=53 \%$

Hal yang sama akan kita lakukan untuk membandingkan ketiga jenis teknik pengkodean dengan teks kedua. Tabel frekuensi teks kedua:

\begin{tabular}{|c|c|c|c|c|c|c|c|}
\hline Char & $\mathrm{K}$ & $\mathrm{U}$ & $\mathrm{Sp}$ & $\mathrm{A}$ & $\mathrm{I}$ & $\mathrm{E}$ & Total \\
\hline Freq & 13 & 4 & 4 & 5 & 1 & 1 & 28 \\
\hline
\end{tabular}

Dengan tabel frekuensi yang telah kita dapatkan, kita dapat melakukan kompresi data terhadap teks kedua terlebih dahulu menggunakan teknik Fixed-Length code. Prosesnya kita akan merepresentasikan tiap karakter menjadi kode biner yang unik, sehingga kita dapatkan tabel untuk kode biner dengan Fixed Length code sebagai berikut:

\begin{tabular}{|l|l|}
\hline Char & Kode Biner \\
\hline K & 000 \\
\hline
\end{tabular}




\begin{tabular}{|l|l|}
\hline U & 001 \\
\hline $\mathrm{Sp}$ & 010 \\
\hline $\mathrm{A}$ & 011 \\
\hline $\mathrm{I}$ & 100 \\
\hline $\mathrm{E}$ & 101 \\
\hline
\end{tabular}

Tabel 7. Kode Biner Fixed-Length code

Sehingga teks kedua jika direpresentasikan kedalam bentuk biner menjadi $0000010000010 \ldots$, yang apabila diteruskan kita akan mendapatkan 84 bit biner.

Sehingga dengan teknik FixedLength code, kita akan mendapatkan rasio kompresi terhadap data awal sebesar:

Rasio Kompresi $=\frac{224-84}{224} \times 100 \%=62.5 \%$

Dengan menggunakan VariableLength code, kita terlebih dahulu melakukan Stable Sorting terhadap tabel frekuensi untuk teks kedua sehingga didapatkan tabel baru yang telah disorting sebagai berikut:

\begin{tabular}{|c|c|c|c|c|c|c|}
\hline Char & $\mathrm{K}$ & $\mathrm{A}$ & $\mathrm{U}$ & $\mathrm{Sp}$ & $\mathrm{I}$ & $\mathrm{E}$ \\
\hline Freq & 13 & 5 & 4 & 4 & 1 & 1 \\
\hline
\end{tabular}

Selanjutnya kita membangun pohon biner untuk tabel tersebut:

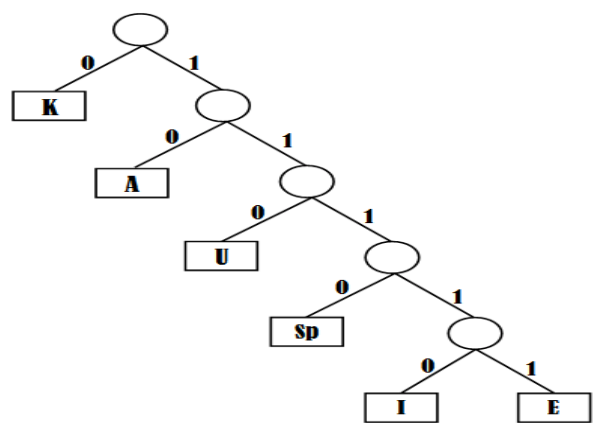

Gambar 3. Pohon biner VLC untuk teks II

Dari pohon biner diatas, kita bisa merepresentasikan setiap karakter berdasarkan kode-kode biner berikut:

\begin{tabular}{|l|l|}
\hline Char & Kode Biner \\
\hline K & 0 \\
\hline A & 10 \\
\hline U & 110 \\
\hline Sp & 1110 \\
\hline I & 11110 \\
\hline E & 11111 \\
\hline
\end{tabular}

Tabel 8. Kode Biner Variable-Length code Sehingga apabila teks direpresentasikan kedalam bentuk biner menjadi $0110011011100 \ldots$, yang apabila diterukan kita akan mendapatkan panjang data sebesar 61 bit.

Sehingga dengan teknik VariableLength code, kita akan mendapatkan rasio kompresi terhadap data awal sebesar:

Rasio Kompresi $=\frac{224-61}{224} \times 100 \%=72 \%$

Yang terakhir kita akan melakukan kompresi data dengan algoritma Huffman, sama halnya dengan Variable Length code, dengan algoritma Huffman kita juga menggunakan tabel frekuensi data yang sudah disorting. Dengan langkah-langkah pada algoritma Huffman, kita akan mendapatkan pohon biner (biasa disebut pohon Huffman) sebagai berikut:

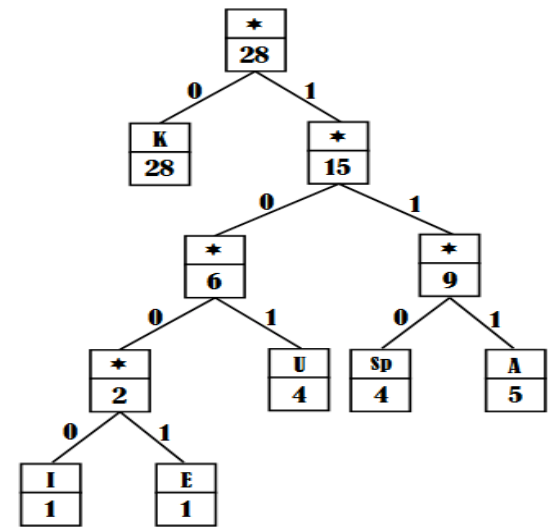

Gambar 4. Pohon Huffman untuk teks II 
Dari pohon Huffman diatas, kita bisa merepresentasikan tiap-tiap karakter pada teks dengan kode-kode biner berikut:

\begin{tabular}{|l|l|}
\hline Char & Kode Biner \\
\hline K & 0 \\
\hline A & 101 \\
\hline U & 110 \\
\hline Sp & 111 \\
\hline I & 1000 \\
\hline E & 1001 \\
\hline
\end{tabular}

Tabel 1. Kode Biner algoritma Huffman

Dengan kode biner yang didapatkan dari pohon Huffman, kita bisa merepresentasikan teks pertama dalam bentuk biner menjadi $011001101110101 \ldots$, dan apabila diterukan kita akan mendapatkan panjang data sebesar 60 bits.

Sehingga dengan algoritma Huffman, kita akan mendapatkan rasio kompresi terhadap data awal sebesar:

Rasio Kompresi $=\frac{224-60}{224} \times 100 \%=73 \%$

\section{Kesimpulan}

Berdasarkan analisis terhadap ketiga teknik kompresi data yaitu Fixed-Length code, Variable-Length code dan Algoritma Huffman didapat beberapa kesimpulan yaitu:

1. Dari ketiga teknik tersebut, proses kompresi data menggunakan Algoritma Huffman memiliki rasio kompresi yang paling tinggi, tetapi memiliki kompleksitas di dalam penyunsunan pohon Huffman.

2. Algoritma Huffman menggunakan prinsip Algoritma Greedy dalam menyusun pohon Huffman.

3. Diantara teknik Fixed-Length code dan Variable-Length code memiliki rasio kompresi yang berbeda, tergantung dari jenis dan besarnya teks yang akan dikompresi. FixedLength lebih efektif untuk teks I, sedangkan Variable-Length lebih efektif untuk teks kedua.

6. Daftar Pustaka

[1] Blelloch, G.E., 2001, Introduction to Data Compression. Computer Science Department, Carnegie Mellon University.

[2] Cormen, T.H, Charles E.L., Ronald L.R., and Clifford S. 2001. Introduction to Algoritms. Second Edition. London: McGraw-Hill Book Company.

[3] Haryanto, R.I., 2009. Kompresi Data dengan Algoritma Huffman dan Perbandingannya dengan Algoritma LZW dan DMC, Makalah IF2091 Strategi Algoritmik.

[3] Schindler, M., Practical Huffman Coding.

http://www.compressconsult.com/huffma n/ Diakses 25 Januari 2012.

[4] Silalahi, B.P., Julio A., Danny D.S. Perbandingan Algoritma Huffman Statik dengan Algoritma Huffman Adaptif pada Kompresi Teks. Jurnal Penelitian.

[5] Wikimedia, Huffman Coding. http://en.wikipedia.org/wiki/Huffman_co ding. Diakses 27 Januari 2011. 